\title{
Study on Prevalence of Ovine Lungworm in Goba District, Bale Zone, South East Ethiopia
}

\author{
Hussen Yunus ${ }^{\alpha}$, Jabir Ame ${ }^{\sigma}$, Seifudin Kassim ${ }^{\rho}$, Mukarim Abdurahaman ${ }^{\beta}$ \\ ${ }^{\boldsymbol{\sigma}, \boldsymbol{\beta}}$ Jimma University, College of Agriculture and Veterinary Medicine (JUCAVM). \\ ${ }^{\boldsymbol{a}, \boldsymbol{\rho}}$ Goba Wereda Livestock and fisheries resource development office.
}

\begin{abstract}
A cross-sectional study was conducted in Goba district, Bale zone, south east Ethiopia, from November, 2015 to March, 2016 with aim of determining the prevalence of ovine lungworm infection, to assess associated risk factors, and identification of species of lungworm which circulate in study area by using coproscopic examination and questionnaire survey. In this study faecal samples were randomly collected from 384 sheep of different age groups, body conditions, sexes and PAs with various altitudes. Then, (L1) were extracted by Modified Baerman technique and examined under low magnification power of Compound Microscope. The finding indicate that 217 (56.5\%) were infected with different species of lungworm; namely, Dictyocaulus filaria (28.4\%), Muellerius capillaries (10.7\%), Protostrongylus rufescens (7.6\%), and mixed infection (9.9\%). There were statistically significant difference $(p<0.05)$ in the prevalence of lungworm infection with regard to age ( $\leq 1$ year $62.0 \%$ and $>1$ year 51.0\%) and PAs (Faasil angeesso 78.1\%, Illasa $52.1 \%$ and Ashuuta 39.1\%); however, sexes (female 59.9\% and male 53.1\%) and body conditions (poor 60.9\%, medium 57.0\%, and good 51.6\%) were insignificant ( $p>0.05)$. In Parallel, questionnaire surveys on history of antihelmintic usage, manifestation of respiratory signs, and place where animal kept were undertaken on the same animals that were sampled for coproscopic examination. Accordingly, the prevalence of lungworm infection with antihelmintic usage (none dewormed $67.5 \%$ and dewormed $44.6 \%$ ), manifestation of respiratory sign (No 44.1\%, and yes 68.2\%), and place where animal kept (forest area 38.1\%, and swampy 67.9\%) and statistically all considered factors for questionnaire survey are highly significant $(p=0.000)$. As conclusion, our work revealed that lungworm belongs to the major respiratory helminthes that affect the health and productivity of sheep in the study area; therefore, attention should be given for the control and prevention to reduce the current high prevalence.
\end{abstract}

Keywords: Bale, Ethiopia, Goba, Lungworm, Ovine, Prevalence

\section{INTRODUCTION}

Ethiopia lies within the tropical latitudes of Africa, and has an extremely diverse topography, a wide range of climatic features and a multitude of agro-ecological zones, which makes the country suitable for different agricultural production systems. This in turn has contributed to the existence of a large diversity of farm animal genetic resources in the country (Anon, 1998a; Anon, 2004b). Ethiopia with its estimated 24.2 million sheep together with its variation in agro climatic zones represents a good reservoir of small ruminant genotypes (CSA, 2012).

Unlike the large potential of small ruminants in the country, their productivity is low. The major problems that greatly affect the economy of sheep and goat production in Ethiopia were diseases (Bekele et al., 1992). Disease alone accounts for 30\% mortality in young's and $20 \%$ in adults. A loss of US\$ 81.8 million is reported annually due to parasite infection. In a country confronted with such enormous losses caused by parasites, it is great loss to the country (Demelash et al., 1999).

Helminth parasite of ovine is ubiquitous, with many tropical and sub-tropical environment of the world providing nearly perfect conditions for their survival and development (Hansen and Perry, 1994). Helminthosis is one of considerable significance in a wide range of agro-climatic zones in SubSaharan Africa and constitute one of the most important constraints to small ruminant production (ILCA, 1990). The production loss is a direct result of clinical and subclinical helminthes infections resulting in low productivity due to stunted growth, insufficient weight gain, poor feed utilization and mortality and indirect losses associated with treatment and control costs (Ayalew et al., 2011). 
In the highland areas, infection with lungworm parasites is the common cause of high mortality and morbidity in sheep population (FAO, 2002). Lungworms are parasitic nematodes known for infection of the lower respiratory tract, characterized by respiratory distress, trachaeitis, bronchitis, and pneumonia (Kimberling, 1988). Common lungworms in sheep are: Dictyocaulus filaria, Muellerius capillaries, and Protostrongylus rufescens (Radostits et al., 2007). These nematodes belong to two super families, Trichostrogyloidea (D. filaria) and Metastrongyloidea ( $P$. rufescens and $M$. capillaries) (Urquhart et al., 1996; Radostits et al., 2007). Dictyocaulidae and certain Metastrongyloidea are known to exist in East Africa (Ethiopia, Kenya and Tanzania) and South Africa (Torncy, 1989). Endoparasites, including D. filaria, are major cause of death and morbidity in the Ethiopian highlands. Up to half of all sheep deaths and morbidity on farms in Ethiopia highlands are caused by pneumonia and endoparasites (ILCA, 1990).

Primary finding of lungworm infection in Ethiopia ((Bekele et al., 1981), (Netsanet, 1992), (Wondwossen, 1992), (Paulos, 2000), (Mihreteab and Aman, 2011), in Arsi and Wollo, Debre Birhan, Asella, Chilalo, and Tiyo respectively) with prevalence of $59.40 \%, 73.25 \%, 39.79 \%, 30.74 \%$, and 57.1 , respectively. It was indicated the high prevalence of lungworm infection in certain parts of the country; however, there was nothing research done on Ovine lungworm in Goba district, Bale zone, Oromia regional state, south east Ethiopia. Therefore, the objectives of this research were the followings:-

- To determine the prevalence of lungworm infection

- To identify the circulating species and associated risk factors for its occurrence

\section{MATERiAls AND Methods}

\subsection{Study Area}

This study was conducted in Oromia Regional State; Bale zone; Goba district which is located $445 \mathrm{kms}$ south east of Addis Ababa at altitude of 2400-4377 m.a.s.l. The area was found at the latitude of $5^{\prime} 0$ ' $\mathrm{N}$ and $40^{\prime} 0^{\prime} \mathrm{E}$. The area covers $177302 \mathrm{~km}^{2}$ in range lands. The area is bordered by different district such as, Sinaana by north; Haranna Buluk and Dallo Manna by south; Adaba and Dinsho by west, and Berbare by east. Topographically, it has $84 \%$ high land, $11 \%$ "weynadega", land and 5\%"wurch", cold moist temperature, It receives an annual range of rain fall from 1150-1400 mm, and the annual range of temperature from $4-24^{\circ} \mathrm{c}$. It receives bimodal rainfall occurring from March to April (a short rainy season) and from July to October (long rainy season). It has a total of 198268 livestock of which 63405 were sheep (GWRAD, 2013).

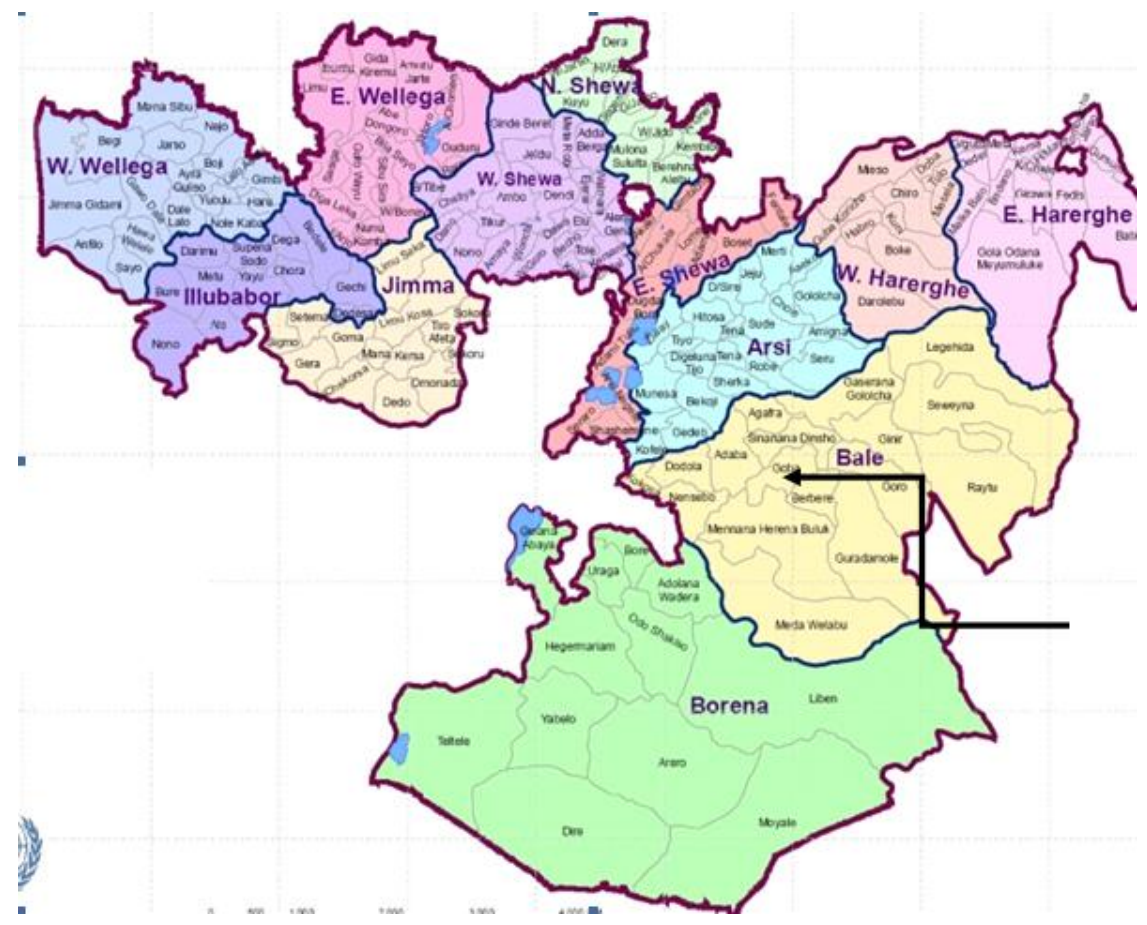

Figure1. Map of administrative region, Zone and Woreda of Oromia including my study site (Goba) Source: (DRMFSS, 2004) 


\subsection{Study Population}

The study population comprises of indigenous Arsi-Bale sheep breed from three agro-ecological areas (highland, midland and Wurch); kept under similar extensive management system; young or adult; all body conditions (poor, moderate, good); dewormed or non-dewormed by antihelmintic; kept in forest or swampy area; apparent health or not were included.

\subsection{Study Design and Sample Size Determination}

Out of 15 villages of Goba district, three namely, Faasil Angeesso with sheep population 2583, Illasa with sheep population 1439, and Ashuuta with sheep population 1349 were purposively selected considering their representation of the highland, midland and Wurch of the district, respectively. Faasil Angeesso is located at an altitude of 2700- 3000 m.a.s.l.; Illasa is situated at altitude of 22002500 m.a.s.l. and Ashuuta is located at altitude of 2500- 2800 m.a.s.l. The households and individual animals were selected using simple random sampling technique. Accordingly, equal proportions of animals were selected for the study i.e. 128 each from each selected PAs. During sampling age, sex, body conditions, antihelmintic usage, appearance of symptoms, and grazing area of the animals were recorded.

The sample size of this study was determined based on internationally set standard formula in (Thrusfield, 2005). Therefore, the sample size for this study was determined using standard formula indicated below.

$$
\frac{\mathrm{N}=1.96^{2} \cdot \mathrm{P}_{\exp }\left(1-\mathrm{p}_{\exp }\right)}{\mathrm{d}^{2}}
$$

Where, $\mathrm{N}=$ required sample size

$\mathrm{P}_{\text {exp }}=$ expected prevalence

$\mathrm{d}=$ desired level of precision $(5 \%)$

There was no previously documented Ovine lungworm infection in study area. As stated above, confidence level chosen is $95 \%$ so that $\mathrm{d}=5 \%$ and expected prevalence is $50 \%$. By substituting the value, the required sample size was 384 .

\subsection{Study Methodology}

\subsubsection{Sample Collection and Laboratory Diagnosis}

Fresh fecal samples collected from the rectum of the animals were immediately transported to Goba Veterinary clinic for processing. Five grams of faeces were weighed from each sample for extraction of L1 larvae using Modified Baerman techniques according to (Anne and Gary, 2006). The faeces were fully enclosed in cheese cloth fixed with metallic stick (a graph) rest on the edges of the funnel glass. The glass was filled with clean hot water until the sample became submerged making sure that the corners of the cheese cloth did not hang over the edge of the funnel. The sample was allowed to sit overnight. Larvae were collected and morphologically identified as described by (Urquhart et al., 1996; Anne and Gary, 2006).

\subsubsection{Questionnaire Survey}

Semi structured questionnaire survey was carried out to interview individual owners of 384 sheep taken for coproscopic examination in order to obtain general information about antihelmintic usage, symptoms of respiratory signs, and grazing area.

\subsection{Data Management and Statistical Analysis}

Raw data and the results of parasitological examination were entered in to a Microsoft Excel spread sheets program. Simultaneously, it were transferred and analyzed by SPSS version 16 software program. The prevalence of lungworm infection was calculated by dividing positive samples for the total number of samples examined. The association between different variables and outcome variables was evaluated using Chi-square $\left(\mathrm{X}^{2}\right)$ test. For all analysis, a p-value less than 0.05 at $95 \%$ confidence level were taken as significant. 


\section{ReSUlts}

\subsection{Over all Prevalence of Lungworm Infection}

Out of 384 sheep faecal examined, $217(56.5 \%)(\mathrm{CI}=51.38 \%-61.5 \%)$ were infected with different species of lungworm. Out of these $28.4 \%, 10.7 \%, 7.6 \%$, and $9.9 \%$, was due to D.filaria, M.capillaries, P.rufescens, and mixed infection, respectively. Thus, D. filaria was the most dominant species followed by $M$. capillaries; P.rufescens was the least, and certain investigated animals were infected by mixed infection. There was statistical significance difference between $D$. filaria and other species of lungworm identified ( $\mathrm{p}<0.05)$ (Table 1) (Figure 2).

Table1. Prevalence of different species of lungworm in total examined sheep

\begin{tabular}{|l|l|l|l|l|l|l|}
\hline Species of lungworm & No. examined animals & No. positive & Prevalence (\%) & Df & $\mathrm{X}^{2}$ & $\mathrm{p}$-value \\
\hline D. filaria & 384 & 109 & 28.4 & 3 & 3.84 & 0.00 \\
\hline M. capillaries & 384 & 41 & 10.7 & & & \\
\hline P. rufescens & 384 & 29 & 7.6 & & & \\
\hline Mixed infection & 384 & 38 & 9.9 & & & \\
\hline Total & 384 & 217 & 56.5 & & & \\
\hline
\end{tabular}

$*$ No.examd animal $=$ number of examined animals; $* D f=$ degree of freedom; $* X^{2}=$ Chi- square

Bar Chart

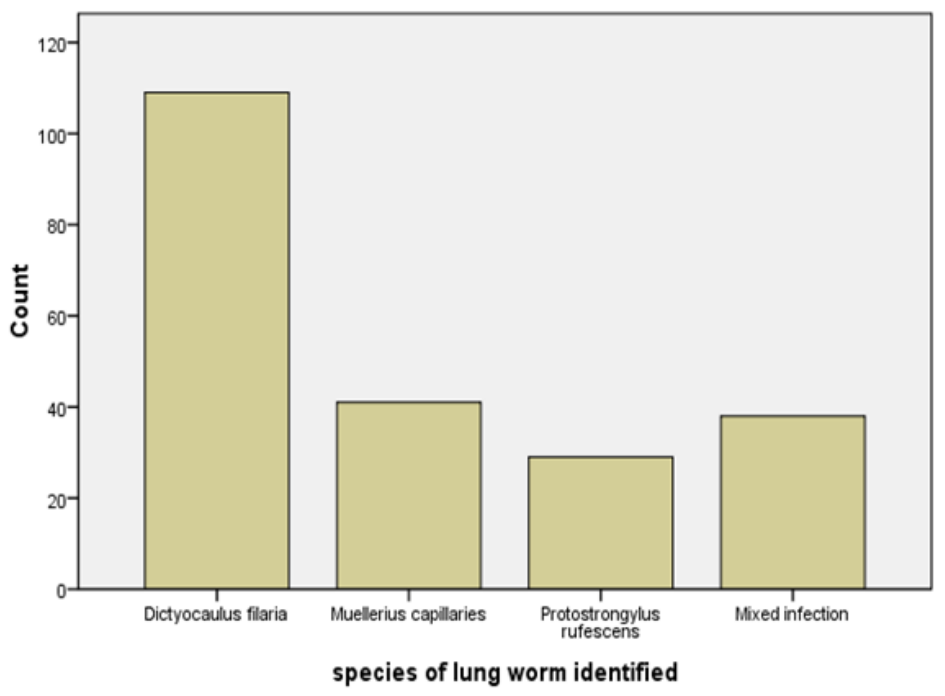

Figure2. Frequency of different species of lungworm identified in total examined sheep

\subsection{Risk Factors and Prevalence of Lungworm Infection}

Prevalence of lungworm infection was determined based on altitude; age, sex, and body conditions of study animals.

\subsubsection{Prevalence of Lungworm Infection According to PAs with Various Altitudes}

Based on altitude and climatic condition, the prevalence was found to be to be $78.1 \%, 52.3 \%$, and $39.1 \%$ in high land (Faasil angeesso), mid-land (Illasa), and Wurch (Ashuuta) respectively. Dictyocaulus filaria and Mueller capillaries were most prevalent in high land while protostrongylus rufescens was most prevalent in midland. Statistically there was significant difference among different PAs with different altitudes $(\mathrm{p}<0.05)$ (Table 2).

Table2. Prevalence of lungworm infection among PAs with various altitudes

\begin{tabular}{|l|l|l|l|l|l|l|l|}
\hline \multirow{2}{*}{ PAs } & No. examined & \multirow{2}{*}{ No. positive } & \multicolumn{3}{|l|}{ Prevalence of different species of lungworm } & \multirow{2}{*}{ Total P (\%) } \\
\cline { 4 - 7 } & & & $D f(\%)$ & $\operatorname{Mc}(\%)$ & $\operatorname{Pr}(\%)$ & $\mathrm{Mi}(\%)$ & \\
\hline Faasil angeesso & 128 & 100 & $53(41.4)$ & $20(15.6)$ & $8(6.2)$ & $19(14.8)$ & 78.1 \\
\hline Illasa & 128 & 67 & $25(12.5)$ & $11(8.6)$ & $15(11.7)$ & $16(12.5)$ & 52.3 \\
\hline Ashuuta & 128 & 50 & $31(24.2)$ & $10(7.8)$ & $6(4.7)$ & $3(2.3)$ & 39.1 \\
\hline Total & 384 & 217 & $109(28.4)$ & $41(10.7)$ & $29(7.6)$ & $38(9.9)$ & 56.5 \\
\hline
\end{tabular}

$\left(X^{2}=42.093 ; d f=2 ; p=0.000\right)$

$* P=$ prevalence $* D f=D$. filaria, $M c=M$. capillaries, $P r=P$. rufescens, Mi=Mixed infection 


\subsubsection{Prevalence of Lungworm Infection According to Sex of Study Animals}

Prevalence of lungworm infection according sex of animals was $53.1 \%$ and $59.9 \%$ in male and female respectively. Prevalence was higher in female than male; however, statistically there was insignificant difference between sex ( $p>0.05)$ (Table 3).

Table3. Prevalence of lungworm infection according to sex of study animals

\begin{tabular}{|l|l|l|l|l|l|l|l|}
\hline Sex & \multirow{2}{*}{$\begin{array}{l}\text { No. } \\
\text { Examined }\end{array}$} & \multirow{2}{*}{$\begin{array}{l}\text { No. } \\
\text { Positive }\end{array}$} & \multicolumn{4}{|l|}{ Prevalence of different species of lungworm } & Total \\
\cline { 5 - 7 } & & $D f(\%)$ & $M c(\%)$ & $\operatorname{Pr}(\%)$ & Mi $(\%)$ & P $(\%)$ \\
\hline Male & 192 & 102 & $48(25)$ & $23(12)$ & $15(7.8)$ & $16(8.3)$ & 53.1 \\
\hline Female & 192 & 115 & $61(31.8)$ & $18(9.4)$ & $14(7.3)$ & $22(11.5)$ & 59.9 \\
\hline Total & 384 & 217 & $109(28.4)$ & $41(10.7)$ & $29(7.6)$ & $38(9.9)$ & 56.5 \\
\hline
\end{tabular}

$\left(X^{2}=1.791 ; d f=1 ; p=0.181\right)$

\subsubsection{Prevalence of Lungworm Infections in Different Age Groups of Animals}

The prevalence of lungworm infection according to age of study animals was $62 \%$ in less than one year and 51\% in greater than one year. Dictyocaulus filaria was higher in less than one year while Protostrongylus rufescens was slightly higher in greater than one year. The prevalence of lungworm infection between age of study animals was statistically significant $(\mathrm{p}<0.05)$ (Table 4).

Table4. Prevalence of lungworm infections in different age groups of animals

\begin{tabular}{|c|c|c|c|c|c|c|c|}
\hline \multirow[t]{2}{*}{ Age } & \multirow{2}{*}{$\begin{array}{l}\text { No. } \\
\text { examined }\end{array}$} & \multirow{2}{*}{$\begin{array}{l}\text { No. } \\
\text { positive }\end{array}$} & \multicolumn{4}{|c|}{ Prevalence of different species of lungworm } & \multirow{2}{*}{$\begin{array}{l}\text { Total } \\
\text { P (\%) }\end{array}$} \\
\hline & & & $D f(\%)$ & $M c(\%)$ & $\operatorname{Pr}(\%)$ & $\operatorname{Mi}(\%)$ & \\
\hline$\leq 1$ year & 192 & 119 & $64(33.3)$ & $23(12)$ & $12(6.2)$ & $20(10.4)$ & 62.0 \\
\hline$>1$ year & 192 & 98 & $45(23.4)$ & $18(9.4)$ & $17(8.9)$ & $18(9.4)$ & 51 \\
\hline Total & 384 & 217 & $109(28.4)$ & $41(10.7)$ & $29(7.6)$ & $38(9.9)$ & 56.5 \\
\hline
\end{tabular}

$\left(X^{2}=4.673 ; d f=1 ; p=0.31\right)$

\subsubsection{Prevalence of Lungworm Infection in Different Body Conditions of Study Animals}

Prevalence of lungworm infection according to body condition of study animals was $60.9 \%, 57.0 \%$, and $51.6 \%$ in poor, medium, and good, respectively. Thus, prevalence of lungworm was highest in poor body condition than others. Dictyocaulus filaria was almost equal in all body condition; Muellerius capillaries and Protostrongylus rufescens were highest in medium and poor body conditions, respectively. Prevalence of lungworm infection according body condition conditions was statistically insignificant ( $\mathrm{p}>0.05)$ (Table 5).

Table5. Prevalence of lungworm infection in different body condition of study animals

\begin{tabular}{|l|l|l|l|l|l|l|l|}
\hline \multirow{2}{*}{$\begin{array}{l}\text { Body } \\
\text { condition }\end{array}$} & \multirow{2}{*}{$\begin{array}{l}\text { No. } \\
\text { examined }\end{array}$} & \multirow{2}{*}{$\begin{array}{l}\text { po. } \\
\text { positive }\end{array}$} & \multicolumn{2}{|l|}{$\mathrm{P}(\%)$ of different species of lungworm } & Total \\
\cline { 5 - 7 } & & $\mathrm{D}(\%)$ & $M c(\%)$ & $\operatorname{Pr}(\%)$ & Mi $(\%)$ & $\mathrm{P}(\%)$ \\
\hline Poor & 128 & 78 & $38(29.7)$ & $12(9.4)$ & $15(11.7)$ & $13(10.2)$ & 60.9 \\
\hline Medium & 128 & 73 & $36(28.1)$ & $20(15.6)$ & $9(7.0)$ & $8(6.2)$ & 57.0 \\
\hline Good & 128 & 66 & $35(27.3)$ & $9(7.0)$ & $5(3.9)$ & $17(13.3)$ & 51.6 \\
\hline Total & 384 & 217 & $109(28.4)$ & $41(10.7)$ & $29(7.6)$ & $38(9.9)$ & 56.5 \\
\hline
\end{tabular}

$\left(X^{2}=2.310 ; d f=2 ; p=0.315\right)$

\subsection{Questionnaire Survey and Prevalence of Lungworm Infection}

Prevalence of lungworm infection during questionnaire survey was assessed based on anthelmintics usage, manifestation of respiratory signs, and grazing area.

\subsubsection{Prevalence of Lungworm Infections in Relation to Antihelmentics Usage in Study Animals}

Prevalence of lungworm infection in study animals in relation to dewormed by anthelmintics or nondewormed was $44.6 \%$ and $67.5 \%$, respectively and it's statistically significant $(\mathrm{p}<0.05)$. Thus, almost prevalence of all lungworm species was higher in non-dewormed animals $(\mathrm{p}<0.05)$, (Table 6). 
Hussen Yunus et al.

Table6. Prevalence of lungworm infection in relation antihelmintic usage in study animals with response of respondents

\begin{tabular}{|c|c|c|c|c|c|c|c|c|}
\hline \multirow{2}{*}{\multicolumn{2}{|c|}{$\begin{array}{l}\text { Did you deworm your } \\
\text { sheep? }\end{array}$}} & \multirow{2}{*}{$\begin{array}{l}\text { No.examd } \\
\text { with rr }\end{array}$} & \multirow{2}{*}{$\begin{array}{l}\text { No. } \\
\text { positive }\end{array}$} & \multicolumn{4}{|c|}{$\mathrm{P}(\%)$ of different species of lungworm } & \multirow{2}{*}{$\begin{array}{l}\text { Total } \\
\mathrm{P}(\%)\end{array}$} \\
\hline & & & & $D f(\%)$ & $M c(\%)$ & $\operatorname{Pr}(\%)$ & $\operatorname{Mi}(\%)$ & \\
\hline \multirow[b]{3}{*}{ Responses } & Yes & 184 & 82 & $41(22.3)$ & $10(5.4)$ & $15(8.2)$ & $16(8.7)$ & 44.6 \\
\hline & No & 200 & 135 & $68(34.0)$ & $31(15.5)$ & $14(7.0)$ & $22(11)$ & 67.5 \\
\hline & Total & 384 & 217 & $109(28.4)$ & $41(10.7)$ & $29(7.6)$ & $38(9.9)$ & 56.5 \\
\hline
\end{tabular}

$\left(X^{2}=20.51 ; d f=1 ; p=0.00\right)$

$* p=$ prevalence, *No.examd with $r r=$ number of examined animals with response of respondents

\subsubsection{Association between Prevalence of Lungworm Infection and Manifestation of Respiratory Signs}

Prevalence of lungworm infection in study animals according to manifestation of respiratory signs was $44.1 \%$ and $68.2 \%$ in apparently health and diseased, respectively and it's statistically significant $(\mathrm{p}<0.05)$. Prevalence of all species of lungworm was higher in those that manifest respiratory signs (Table 7).

Table7. Association between prevalence of lungworm infection and respiratory signs with response of respondents

\begin{tabular}{|l|l|l|l|l|l|l|l|l|}
\hline \multirow{2}{*}{ Did your sheep cough? } & \multirow{2}{*}{$\begin{array}{l}\text { No. } \\
\text { examined } \\
\text { with rr }\end{array}$} & $\begin{array}{l}\text { No. } \\
\text { Positive }\end{array}$ & \multicolumn{2}{l|}{$\begin{array}{l}\text { P }(\%) \text { of different species of } \\
\text { lungworm }\end{array}$} & \multicolumn{2}{l|}{$\begin{array}{l}\text { Total } \\
\text { P }(\%)\end{array}$} \\
\cline { 3 - 9 } & & & $D f(\%)$ & $M c(\%)$ & $\operatorname{Pr}(\%)$ & Mi $(\%)$ & \\
\hline \multirow{3}{*}{ Responses } & Yes & 198 & 135 & $67(33.8)$ & $25(12.6)$ & $22(11.1)$ & $21(10.6)$ & 68.2 \\
\cline { 2 - 9 } & No & 186 & 82 & $42(22.6)$ & $16(8.6)$ & $7(3.8)$ & $17(9.1)$ & 44.1 \\
\cline { 2 - 9 } & Total & 384 & 217 & $109(28.4)$ & $41(10.7)$ & $29(7.6)$ & $38(9.9)$ & 56.5 \\
\hline
\end{tabular}

$\left(X^{2}=22.658 ; D f=1 ; p=0.000\right)$

*No.exmined with $r r=$ number of examined animals with response of respondents

\subsubsection{Association between Prevalence of Lungworm Infections and Grazing Area}

The prevalence of lungworm infection in study animals according to grazing area was $67.9 \%$ and $38.1 \%$ in swampy and forest grazing animals, respectively. Thus, infection was higher in swampy grazing animals. Prevalence of all species of lungworm was higher in swampy area. The prevalence of lungworm infection according to grazing area was statistically significant $(\mathrm{p}<0.05)$ (Table 8$)$.

Table8. Association between prevalence of lungworm infections and grazing area with response of respondents

\begin{tabular}{|c|c|c|c|c|c|c|c|c|}
\hline \multirow{2}{*}{\multicolumn{2}{|c|}{$\begin{array}{l}\text { Where do you keep your } \\
\text { sheep? }\end{array}$}} & \multirow{3}{*}{$\begin{array}{l}\text { No.exmd } \\
\text { with rr } \\
237\end{array}$} & \multirow{3}{*}{$\begin{array}{l}\begin{array}{l}\text { No. } \\
\text { positive }\end{array} \\
161\end{array}$} & \multicolumn{4}{|c|}{$\mathrm{P}(\%)$ of different species of lungworm } & \multirow{2}{*}{$\begin{array}{l}\text { Total } \\
\mathrm{P}(\%)\end{array}$} \\
\hline & & & & $D f(\%)$ & $M c(\%)$ & $\operatorname{Pr}(\%)$ & $\operatorname{Mi}(\%)$ & \\
\hline \multirow[t]{3}{*}{ Responses } & $\begin{array}{l}\text { Swampy } \\
\text { areas }\end{array}$ & & & $79(33.3)$ & $32(13.5)$ & $19(8.0)$ & $31(13.1)$ & 67.9 \\
\hline & Forest & 147 & 56 & $30(20.4)$ & $9(6.1)$ & $10(6.8)$ & $7(4.8)$ & 38.1 \\
\hline & Total & 384 & 217 & $109(28.4)$ & $41(10.7)$ & $29(7.6)$ & $38(9.9)$ & 56.5 \\
\hline
\end{tabular}

$\left(X^{2}=32.85 ; d f=1 ; p=0.00\right)$

*No.examd with $r r=$ number of examined animal with response of respondents

\section{DisCUSSIONS}

The result of present study conducted from November, 2015 to March, 2016 in three PAs of Goba district, Bale Zone, south-east of Ethiopia indicated that lungworm infection was one of the most common respiratory diseases of sheep with an overall prevalence of $56.5 \%$. This agrees with the research findings that were conducted in Asella by (Bekele et al., 1981), (Wondwossen, 1992), (Paulos, 2000), (Mihreteab and Aman, 2011), (Hasen et al., 2013), (Hussein et al., 2017) and ( Kadi et al., 2017) with prevalence of 59.4\%, 58.8\%, 52.54\%, 57.1\%, 55.10\%, 59.9\% and 51.0\% respectively; (Teffera, 1993) in Dessie and Kombolcha, 50\%. However, the current finding was lower than the prevalence reported by (Eyob and Mathios, 2013) in Asella province, 72.44\%; (Yohannes, 1989) in DebreTabor Awraja, 70.7\%; (Netsanet, 1992) in Debre Birhan, 73.75\% and (Sefinew, 1999) in six district of Wollo, $71.3 \%$. The result of current finding highly disagrees with study conducted by (Frewengel, 1995) in and around Mekele, 13.24\%, and (Ibrahim and Degefa, 2012) in Mekele town, $13.4 \%$. The possible explanation for such prevalence variation could be due to variation in rainfall, 
humidity, altitude, temperature difference, and season of examination on the respective study areas which favor or disfavor the survival of parasite larvae (Soulsby, 1982; Bradford, 2002).

In current study, the prevalence of different species of lungworm was $28.4 \%, 7.6 \%, 10.7 \%$ and $9.9 \%$ due to $D$. filaria, $P$. rufescens, $M$. capillaries, and mixed infection with two or three species of lungworm, respectively. With regard to the species of lungworms, it was observed that $D$. filaria was the most predominant species in the area followed by $M$. capillaries, whereas $P$. rufescens was the least prevalent. This finding is supported by (Alemu et al., 2006), (Mihreteab and Aman, 2011), (Netsanet, 1992) and (Nemat and Moghadam, 2010) who were reported that D. filaria was the most prevalent in their study area. In contrast to this findings, (Sisay, 1996) in Bahirdar and (Mezgebu, 1995) in Addis Ababa reported that M. capillaries was the most prevalent. The possible explanation for the predominance of $D$. filaria in the study area might be attributed to the difference in the life cycles of the parasites. Thus, D. filaria has a direct life cycle and requires shorter time to develop to an infective stage while $M$. capillaries has an indirect life cycle which needs an intermediate snail for completing its life cycle. Thus, require longer time to develop to infective stage. In the present study area, the environment may not favorable to the intermediate host as that of Bahirdar and Addis Ababa that make M.capillaries and P.rufescens lower. According to (Soulsby, 1982) after ingestion the larvae D.filaria parasites can be shed with faeces within five weeks. Compared with D. filaria, the transmission of $P$. rufescens and $M$. capillaries is epidemiologically complex event involving host, parasite and intermediate host. Hence, $M$. capillaries and $P$. rufescens in sheep require slugs or snails as intermediate host which must be eaten for infection to occur; this might make them low prevalent in the present study area than D. filaria (Urquhart et al., 1996). Mixed infection was also observed in the current study as in previous studies (Wondwossen, 1992; Hansen and Perry, 1994; Paulos, 2000).

On attempt to know the influence of altitude on study area, there was statistically significant difference on prevalence of lungworm infection; with prevalence of $78.1 \%, 52.3 \%$, and $39.1 \%$ at high altitude (Faasil angeesso) (2700-3000 m.a.s.l), mid altitude (Illasa) (2200-2500 m.a.s.l) and low altitude (Ashuuta) (1500-1800 m.a.s.l), respectively. These results indicate that, prevalence of lungworm infection increase as altitude increase. This result agrees with study reported by (Mihreteab and Aman, 2011) who reported $66.4 \%, 57.5 \%$, and $47.2 \%$ in high altitude (>2700 m.a.s.l), medium altitude (2100 m.a.s.l), low altitude (1600 m.a.s.l), respectively in Tiyo district. It was also inline within Alemu et al. (2006) findings who had reported 70\%, 47\% and 43\% in high, medium, and low altitude, respectively, in north east of Ethiopia. This finding disagrees with the reports of Wondwossen (1992) who indicated absence of significant difference in different lungworm species distribution between high and mid altitude in Asella Awraja. These differences between researchers might be associated with variation in sample size, duration of study time and season of study period. It may also be associated with climate changes every year which could help in the agro-ecological expansion of previously highlands adapted parasites to medium and low altitude. In this finding prevalence was the highest in high altitude than others; this might be due to it has low temperature, higher moisture and humidity than other ecologies which is favorable for survival of larvae and intermediate hosts (Radostits et al., 2007).

With regard to the prevalence of lungworms in different age groups; young animals were found to be more infected than adult. The higher infection rate was observed in less than a year $(62.0 \%)$ while lower infection rate was observed in greater than a year (51.0). This shows that young were more susceptible than adult. In less than one year, Dictyocaulus filaria was higher $(33.3 \%)$ than greater than one year (23.4\%); however, in greater than one year Protostrongylus rufescens $(8.9 \%)$ was higher than less than one year (6.2\%). This finding agrees with (Mihreteab and Aman, 2011), (Wondwossen, 1992), and (Teferra, 1993) who reported that young sheep were more affected by $D$. filaria than adult sheep. The reason behind this is either due to development of acquired immunity in adult animals from previous exposure or recovered animals have better immunity against re-infection. In the other way, young animals had poorly developed immunity against $D$. filaria. In this finding Protostrongylus rufescens was higher in adults than in young; this might be due to impaired development of acquired immunity in adult or due to young animals may not be exposed to intermediate host (Radostits et al., 2007). This may be also associated with the life cycle and infection route of the parasite which is through ingestion of infected snail (IH) which results to lower infection in young, but accumulate through long time in adults that make them more susceptible. 
On attempt to know the influence of sex, on variation of prevalence of lungworm infection, the prevalence was higher in female (59.9\%) than male (53.1\%), but the difference was statistically insignificant. This agrees with research reported by (Addis et al., 2011), (Nibret et al., 2011), (Eyob and Mathios, 2013), (Dawit and Abdu, 2012) and (Hasen et al., (2013), but disagree with report of (Alemu et al., 2006) and (Mihreteab and Aman, 2011). These differences between researchers might be either due to improper distribution of sample selection between the two sexes that makes prevalence higher in female (Addis et al., 2011) or most of the sampled females are not in preparturient period during the study time that make both sexes equally susceptible to disease. In current finding prevalence was higher in female; this might due to certain sampled animal were lactating which suppress immunity of the animal (Urquhart et al., 1996).

With regard to assess the influence of body condition, on variation of prevalence of lungworm infection, it was found that $60.9 \%, 57 \%$, and $51.6 \%$ in poor, medium, and good, respectively. Hence, prevalence was higher in poor body condition than other; however, variation among body condition was statistically insignificant. This finding agrees with study reported by (Dawit and Abdu, 2012) who said the difference between conditions are insignificant; however, disagrees with study reported by (Mihreteab and Aman, 2011), and (Desta et al., 2013) who reported the variation among body condition was statistically significant. The reason why current finding insignificant among body condition, might be either due to loss of weight cannot only be attributed by the lungworm infection alone but also inappropriate management and other helminth infection (Mengestom, 2008). In this finding even though variation is insignificant prevalence of lungworm infection was higher in poor body condition than other; this might be due to poorly nourished animals are less competent in not to be infected by lungworm than others (Kimberling, 1988).

With attempt to know influence of antihelmintic usage on prevalence of lungworm infection, questionnaire survey findings were tried to associate antihelmintic usage with the faecal examination results. Higher prevalence (67.5\%) of the parasites was recorded in sheep with the respondents that said non-dewormed than dewormed (44.6\%) and it's statistically significant. The observation noted in this study agreed with study reported by (Eyob and Mathios, 2013), (Yohannes, 1989), (Netsanet, 1992) and (Sefinew, 1999). In those mentioned authors, their findings indicate that the prevalence of the parasite was found high in animals that were non-dewormed than dewormed. In current study, even though the dewormed sheep revealed low infection prevalence compared to non-dewormed groups, about $44.6 \%$ of them were infected with lungworm. The reason why dewormed sheep infected might be either due to the antihelmintic used in the area for the treatment only temporarily suppress egg production of the adult worms or parasite may become resistance to antihelmintic used. It may also be related to the poor quality of antihelmintic used in the country. In contrast, $32.5 \%$ of none dewormed animals were not infected by lungworm; this might be due to development of acquired immunity from previous exposure (Blood et al., 1997; Urquhart et al., 1996) and it may also be due to none exposure to the infective stages of $D$. filaria or to intermediate host of the other species of the lungworms of sheep throughout their life.

With regard to know appearance of symptoms of respiratory sign with lungworm infection, questionnaire survey findings were tried to associate manifestation of respiratory sign with the faecal examination results. Higher prevalence $(68.2 \%)$ of the parasites was recorded in sheep with the respondents that said yes (it shows clinical respiratory signs) than that said no (did not show signs) $(44.1 \%)$. Hence, the variation was statistically significant. This finding agreed with the study reported by (Paulos, 2000), (Eyob and Mathios, 2013) and (Hasen et al., 2013). In those mentioned authors, their findings indicate that the prevalence of the parasite was found high in animals which showed symptoms of respiratory signs than apparently healthy. In current finding, even though apparently healthy sheep show low infection compare to those showing clinical respiratory signs groups, about $44.1 \%$ of them were infected with lungworm. The reason why apparently health sheep appeared with lungworm might be due to; the parasites were in pre-patent stage; due to small adult worm burden in sheep which couldn't produce eggs and hence larvae; or as a result of immunity developed due to exposure to a few lungworms which is not associated with clinical sign but animal shed larvae (Soulsby, 1982). 21.8\% of those animals manifesting respiratory signs were appeared negative on coproscopic examination; this might be, due to bacterial or viral diseases that causes occurrence of respiratory signs (Gelagay et al., 2004). 
Lastly, in this study questionnaire survey findings were tried to relate the grazing area with the faecal examination results. Higher prevalence $(67.9 \%)$ of the parasites was recorded in sheep with the respondents that said their kept in swampy area than forest $(38.1 \%)$ and it's statistically significant. Thus, the variation of lungworm infection according to grazing area may be due to antihelmintic effects of some trees and shrubs browsed from the forest that cause prevalence of lungworm infection low in forest grazing sheep (Rahman and Seip, 2006); prevalence in swampy area was high might be due to presence of moisture which is favorable for survival of larvae and intermediate host (Urquhart et al., 1996)

\section{CONCLUSION AND RECOMMENDATIONS}

Lung worms are one of the most common causes of respiratory problem in Ovine. The result of present study revealed that prevalence of Ovine lungworm was high in Goba district, Bale zone. The major lungworm species identified in the study area were: $D$. filaria, M. capillaries, and P. rufescens. D. filaria was identified as the most dominant lungworm species. Coproscopic examination and questionnaire survey revealed that young, none dewormed, clinically diseased, swampy grazing animals, and animals from high and medium altitude were harbor more infection than their counter parts; however, body conditions and sexes doesn't have much influence on variation of lungworm infection.

In view of these facts, the following recommendations are forwarded:-

- Regular deworming with effective antihelmintic should be routinely practiced in the area

- Sheep should be prohibited from grazing swampy areas.

- Young age groups should be isolated during the season when pasture contamination expected

- Emphasis should be given to the control and prevention in order to reduce the prevalence from the current high finding

\section{REFERENCES}

Alemu, S., Gelay, E., Ayele, G. and Zeleke, A. (2006): Study on small ruminant lungworm in North east Ethiopian. J. Vet. Parasitol., 14:330-335.

Anne, M.Z. and Gray, A.C. (2006): Veterinary clinical parasitology. $7^{\text {th }}$ ed., Australia, Blackwell publishing company, $\mathrm{p}_{\mathrm{p}}$. 11-14.

Anon (1998a): Agro-ecological Zones of Ethiopia. Natural resources management and regulatory department, Ministry of Agriculture, Addis Ababa, Ethiopia, $\mathrm{p}_{\mathrm{p} .74}$

Anon (2004b): State of Ethiopian's Animal Genetic Resources- Country Report. A Contribution to the First Report on the State of the World's Animal Genetic Resources. Institute of Biodiversity Conservation (IBC), Addis Ababa, Ethiopia, pp.74.

Ayalew, A., Tewodros, D. and Alemayehu, W. (2011): Prevalence and risk factors of intestinal parasites among Dergi school children, North Gonder, Ethiopia. J. Parasitol. Vector Biol., 3:7581.

Bekele, M., Fesseha, G. and Shibiru, T. (1981): Observation of D.filaria in Wollo and Arsi Administrative Region of Ethiopia. J. Agric. Sci., 3:75

Bekele, T., T., Woldeab, A., Lahlou-lasso and J., Sherington (1992): Factors affecting morbidity onfarm and on-station in Ethiopian highland sheep. Acta. Trop., pp 99-109.

Blood, D.C., Radostitis, O.M., Gray and Hincheeliff, K.W. (2000): Veterinary Medicine a text of book of the disease of Cattle, Sheep, Pigs and Horses. $8^{\text {th }}$ ed., Harcourt Publisher Ltd, London, Pp. 1246-1253.

Bradford, P. (2002): Large Animal Internal Medicine: Disease of horses, cattle, sheep and goats, $3^{\text {rd }}$ ed., Mosby Inc. Pp. 514-515, 1452-1455.

CSA (2012): Agricultural Sample Survey 2011/12 [2004 E.C.]; report on Livestock and Livestock Characteristics (Private Peasant Holdings).Volume II Statistical Bulletin 532, Addis Ababa, Ethiopia.

Dawit, W. and Abdu, M. (2012): Prevalence of Small Ruminant Lung Worm Infection in Jimma Town. Global Vet., 8:153-159. 
Demelash, B., Yilma, J. and Hassen, C. (1999): Ovine Helminthosis is a Major Health Constraint to Productivity of Sheep in Ethiopia, Faculty of Veterinary Medicine, Awassa University, Awassa, Ethiopia.

Desta, B., Sisay, N., Dinka, A. and Fufa, A. (2013): The Prevalence of Lungworms in Naturally infected Sheep of Ambo District, Oromia, Ethiopia. DVM Thesis, Haramaya University, College of Veterinary Medicine Dire Dawa, Ethiopia; Addis Ababa University, College of Veterinary Medicine and Agriculture, Debre Zeit, Ethiopia

DRMFSS, (2004): Disease Risk Management and Food Security Sector Map of administrative region, Zone and Woreda of Oromia

Eyob, E. and Matios, L. (2013): The prevalence and risk factors associated with Ovine lungworm infestation in the Asella province, Central Ethiopia. J. Parasitol. Vector Bio., 5: Pp 118

FAO (2002): Production Year Book. Rome, Italy, 54: 200-315.

Frewengel, S. (1995): Prevalence of Ovine Dictyocaulus in and around Mekelle. DVM Thesis, AAU, FVM, Debrezeit, Ethiopia.

Gelagay, A., Laekemariam, Y., Esayas, G., Selam, T. and Kassahun, A. (2004): Epidemiologic and Serologic Investigation of Multifactorial Respiratory Disease of Sheep in the Central Highland of Ethiopia. Intern. J. Appl. Res. Vet. Med. 2: $\mathrm{p}_{\mathrm{p}}$ 274-275.

GWRAD (2013): Goba Woreda Rural and Agricultural Development: Basic data of Goba Woreda

Hansen, J. and Perry, B. (1994): The epidemiology, diagnosis and control of Helminth parasite of ruminant, ILRAD, Kenya, Pp. 83.

Hasen, A., Tekele, S. and Simenew, K. (2013): Ovine lungworm infestation rate on fecal larvae recovery basis. Acta. Parasitol. Glob., 4: 29-33.

Hussien H., Kasim S., Shibeshi S., and Abdurahaman M., (2017): Prevalence of Lungworm Infection of Small Ruminants in Assela and its Surroundings., Journal of Natural Sciences Research $7(1): 1-8$.

Ibrahim, N. and Degefa, Y. (2012): Prevalence of Ovine Lung Worm Infection in Mekelle Town, North Ethiopia. Int. J. Vet. Med., 9:1-15.

ILCA (1990): Annual Report; ILCA, Addis Ababa, Ethiopia, Pp. 37.

Kadi. K., Baye D., Hussien H., and Abdurahaman M., (2017): Study on Prevalence of Small Ruminants Lungworm in Asella Municipal Abattoir, Arsi Zone, South East Ethiopia., International Journal of Research Studies in Biosciences 5(5):21-32.

Kimberling, C.V. (1988): Jensen and Swift's Diseases of Sheep, $3^{\text {rd }}$ ed., Lea and Febiger, Philadelphia, Pp. 99-101.

Mengestom, G. (2008): preliminary study on prevalence of Ovine Lungworm infection in Asbi. DVM Thesis, Jimma University, Jimma, Ethiopia.

Mezgebu, M. (1995): A survey on ovine fasciolosis and lungworm infection in Addis Ababa and the surrounding highland areas. DVM Thesis, Faculty of Veterinary Medicine, Addis Ababa University, Debrezeit, Ethiopia.

Mihreteab, B. and Aman, A. (2010): Ovine Lungworms in Tiyo District, South east Ethiopia. Prevalence, Effect of Altitude and Major Host Related Risk factors. DVM Thesis School of Veterinary Medicine, Jimma University, Ethiopia.

Nemat, E.A. and Moghadam, G.A. (2010): A Survey on Annual Infestation of Sheep With Lung Worms Based on Fecal Test and Slaughter House Study in Tabriz. J.Vet. Res., 64: 339-342.

Netsanet, B. (1992): Study on prevalence and control of lungworm in local Ethiopian highland sheep in and around Debere birhan. DVM Thesis, FVM, AAU, Debrezeit.

Nibret, M., Basazne, B. and Mersha, C. (2011): Dictyocaulus filaria and Muellerius capillaries are Important Lungworm Parasites of Sheep in Wogera District, Northern Ethiopia. Int. J. Anim. Vet. Adv. 3: 465-468.

Paulos, A. (2000): Importance of Seasonal Dynamics of Lungworms infection of Small Ruminants in Chilalo areas, Arsi Zone. DVM Thesis, FVM, AAU, Debrezeit, Ethiopia.

Radostits, O.M., Gay, C.C., Cliff, K.W.H. and Constable, P.D. (2007): Veterinary Medicine. A Text book of the disease of cattle, horses, sheep, pigs and goats, $10^{\text {th }}$ ed., Bailler, Tindal, London, Pp. 1568-1569. 
Rahman, G and Seip, H. (2006): Alternative strategies to prevent and control endoparasites diseases in organic sheep and goat farming, Pp .71

Sefinew, A. (1999): Survey of small ruminant lungworm in six district of Wollo. DVM Thesis, FVM, AAU, Debrezeit

Sisay, A. (1996): Preliminary study on the prevalence of Ovine lungworm infection in and around Bahirdar. DVM Thesis, FVM, AAU, Debrezeit

Soulsby, E.J.L. (1982): Helminthes, Arthropods and Protozoa of Domesticated Animals, $6^{\text {th }}$ ed., Baillere, Tindal, London, Pp. 499-552.

Teffera, S. (1993): Prevalence of Ovine lungworm around Dessie and Kombolcha. DVM Thesis, FVM, AAU, Debrezeit

Thrusfield, M. (2005): Veterinary epidemiology $2^{\text {nd }}$ ed., Blackwell Science, university of Edinburgh, London, Pp. 180-188.

Torncy, P.M. (1989): Manual of Tropical Veterinary Parasitology. Helminths of Livestock and Poultry in Tropical Africa. The International Technical Center for Agricultural and Rural Cooperation, Pp. 81-85.

Urquhart, G. M., Armour, J.I., Dunn, A. M. and Jennings, F.W. (1996): Veterinary parasitology University of Glasgow, Scotland, Black well science, Ltd, $2^{\text {nd }}$ ed. Pp 41-42; 59-60

Urquhart, G.M., Armous, J., Duncan, J.H. and Jenings, F.W. (1987): Veterinary parasitology, Longman scientific and Technical, USA, Pp. 39- 40; 57-58

Wondwossen, T. (1992): Prevalence of Lungworm in and around Asella. DVM Thesis, FVM, AAU, Debrezeit.

Yohannes, G. (1989): Epidemiological study and antihelmintic trail of ovine Dictyocaulosis in Debretabor Awraja. DVM Thesis, FVM, AAU, Debrezeit. 